\title{
Review Article \\ Positive impact of abiotic stress on medicinal and aromatic plants
}

\author{
J. PRADHAN, S.K. SAHOO, S. LALOTRA AND R.S. SARMA
}

\section{SUMMARY}

Abiotic stress is the imbalance in the environmental status that affects the normal growth, development and reproduction of an organism. Various abiotic stresses are drought, salinity, heat, flood, reactive oxygen species etc. Generally stress cause reduction in quality and quantity of yield in agricultural crops. But in case of medicinal and aromatic plant it has been found to enhance both qualitative and quantitative yield. In this article we are going to understand the mechanism that will change our view towards abiotic stresses.

Key Words : Abiotic stress, Medicinal plants, Quality yield, Advantage of stress

How to cite this article : Pradhan, J., Sahoo, S.K., Lalotra, S. and Sarma, R.S. (2017). Positive impact of abiotic stress on medicinal and aromatic plants. Internat. J. Plant Sci., 12 (2): 309-313, DOI: 10.15740/HAS/IJPS/12.2/309-313.

Article chronicle : Received : 16.01.2017; Accepted : 27.06.2017

Email : jyostna.ouat@gmail.com

Address of the Co-authors:

S.K. SAHOO, Department of Plant Physiology, Agricultural Biochemistry, Medicinal and Aromatic Plants, Indira Gandhi Krishi Viswavidyalaya, RAIPUR (C.G.) INDIA

S. LALOTRA AND R.S. SARMA, Department of Plant Physiology, Institute of Agricultural Sciences, Banaras Hindu University, VARANASI (U.P.) INDIA 